\title{
Psychological impact of congenital adrenal hyperplasia on adolescent and young girls in Saudi Arabia.
}

\author{
Nasir A. M. Al- Jurayyan" ${ }^{*}$, Amal A. Al-Hakami² \\ ${ }^{1}$ Department of Paediatrics, College of Medicine, King Saud University, Saudi Arabia \\ ${ }^{2}$ College of Medicine, Princess Nourah Bint Abdulrahman University, Riyadh, Saudi Arabia
}

\begin{abstract}
Background: Congenital adrenal hyperplasia (CAH) consists of a family of defects in the synthesis of steroid hormone in the adrenal cortex which results in high androgen levels. The androgen excess is present from early embryogenesis and results in varying degrees of virilization of the external genitalia. It can lead to major medical and psycho-social consequences.

Design and setting: Eight Saudi adolescent and young women whose age ranged between 15 to $25 \mathrm{y}$ with variable severity of $\mathrm{CAH}$ were studied to determine the psychosocial impact at the endocrine service, King Khalid University Hospital (KKUH) Riyadh, Saudi Arabia in the period July 2017 to June 2018. Objective: The aim of this study was to determine the psychological impact of CAH on adolescent and young women who were diagnosis and appropriately reared in the early life.

Methods: Eight Saudi adolescent and young women with similar clinical characteristics where chosen from a cohort of sixty four patients with CAH. Psychosocial information were gathering during a clinic visits from both participant and parents. Participants were interviewed by the primary treating endocrinologist (principal author $\mathrm{NJ}$ ) to facilitate trust and confidence, utilizing the child behaviour checklist (CBCL) questioner.

Results: There were significant differences between females with $\mathrm{CAH}$ diagnosed early in life and reared as females with higher incidence of anxiety, depression (25\%), withdrawn/depressed behaviour (25\%) and somatic complaints (75\%), which depend on the variation of the severity.

Conclusion: Psychological adjustment is variable in females with $\mathrm{CAH}$ who were diagnosed and properly reared in early life. Adjustment depends on the severity of the disease. Future multicentre studies involving $\mathrm{CAH}$ patients in Saudi Arabia are needed to ensure large sample size. In addition, further researchers should concentrate on various aspects of psychosocial issues of CAH.
\end{abstract}

Keywords: Psychological impact, Congenital adrenal hyperplasia, Adolescent, Young women, Saudi Arabia.

Accepted on November 23, 2018

\section{Introduction}

Congenital adrenal hyperplasia $(\mathrm{CAH})$ consists of family of defects in the synthesis of steroid hormones in the adrenal cortex. It is caused by a defect in 21-alpha-hydroxylase gene (CYP21) in more than $90 \%$ of the cases. However, the rest were due to 11-beta-hydroxylase enzyme deficiency and 3beta-hydroxysteroid dehydrogenase deficiency. The enzyme deficiency results in impaired synthesis of cortisol and aldosterone. The low cortisol levels result in increased production of adrenocorticotrophic hormone (ACTH) by the pituitary, which cause increase synthesis of steroid precursors resulting in high androgen levels. The androgen excess is present from early embryogenesis and results in varying degrees of virilization of the external genitalia in girls. CAH is the most common reason for ambiguous genitalia at birth. It requires lifelong medications, frequent hospital visits, and genital surgery [1-6]. In Saudi Arabia where the consanguineous matting is high, there are no precise data on the prevalence of the disease; however, there are impression fostered by clinical experience and local reports of congenital adrenal hyperplasia that this is not an uncommon disease. A calculated incidence had been postulated, 1 in 5000, from the number of patients diagnosed with the disease among the deliveries at King Khalid University Hospital (KKUH) Riyadh Saudi Arabia. Presently, the limited local new-born screening program supported such data [3].

Previous studies had shown that $\mathrm{CAH}$ affects all aspects of health-related quality of life, and that adolescent girls and young adult women have an increased risk of psychiatric morbidity. However, there is still a lack of knowledge about quality of life determinants and optimal psychiatric adaptation $[7,8]$.

Although advances in care and medical knowledge have been significantly important, the prognosis for patients living with 
$\mathrm{CAH}$ still need to comply with life restrictions required to manage the disorder, i.e., lifelong medications $[9,10]$.

Further behaviour studies will provide valuable information that would help in determining whether any intervention can be instituted to minimize the long-term effects.

This article reports on our experience at King Khalid University Hospital (KKUH), endocrine service, Riyadh, Saudi Arabia of the psychological impact of $\mathrm{CAH}$ on adolescent and young women.

\section{Material and Methods}

This is a qualitative descriptive study conducted at paediatric endocrine service, King Khalid University Hospital (KKUH) of king Saud University during the period between July 2017 to June 2018.
The aim of this study is to assess the psychological adjustment of adolescent girls and young women with CAH. Eight Saudi Arabian adolescent girls and young women whose age ranged from 15 to $25 \mathrm{y}$ where chosen from a cohort of sixty four patients with variable causes and similar clinical characteristics (Table 1). Prader classification was used to describe masculinization of external genitalia at diagnosis [11]. Genital surgery was done early in life, so nothing remembers about this. Psychosocial information were gathering during a clinic visits from both participant and parents. Participant was interviewed by the primary treating endocrinologist (principal author NJ) to facilitate trust and confidence, utilizing the child behaviour checklist (CBCL) questioner [12]. Statistical package for social science (SPSS) version 21, (Chicago, IL, USA) was used for the statistical analysis of the data.

Table 1. The clinical characteristics of patients with congenital adrenal hyperplasia (CAH).

\begin{tabular}{|c|c|c|c|c|c|c|c|c|}
\hline \multirow{2}{*}{ Serial number } & \multirow{2}{*}{$\begin{array}{l}\text { Age at } \\
\text { study }\end{array}$} & \multirow{2}{*}{ Diagnosis } & \multicolumn{4}{|c|}{ Clinical presentation } & \multirow[t]{2}{*}{$\begin{array}{l}\text { Number of } \\
\text { surgeries }\end{array}$} & \multirow[t]{2}{*}{ Remarks } \\
\hline & & & A.G Prader & sw & sv & Hypertension & & \\
\hline 1 & $18 \mathrm{y}$ & 21-OH-ase deficiency & (4) & + & - & - & 3 & - \\
\hline 2 & $16 y$ & \multirow{5}{*}{$\begin{array}{l}\text { Congenital adrenal } \\
\text { hyperplastic }(\mathrm{CAH})\end{array}$} & (3) & + & - & - & 3 & Sister of " 1 " \\
\hline 3 & $22 \mathrm{y}$ & & (5) & + & - & - & 3 & - \\
\hline 4 & $21 \mathrm{y}$ & & $(5)$ & + & - & - & 3 & - \\
\hline 5 & $15 y$ & & (4) & + & - & - & 2 & - \\
\hline 6 & $25 y$ & & (2) & - & + & - & 1 & - \\
\hline 7 & $18 y$ & \multirow{2}{*}{$\begin{array}{l}\text { 11-OH-ase deficiency } \\
\mathrm{CAH}\end{array}$} & (5) & - & - & $+(14 \mathrm{y})$ & 3 & - \\
\hline 8 & $14 \mathrm{y}$ & & (4) & - & - & $+(10 \mathrm{y})$ & 2 & Sister of "7" \\
\hline
\end{tabular}

A.G: Ambiguous Genitalia; SW: Salt-Wasting; SV: Simple Vililizing; Prader: Prader Classification; y: year; 21-OH-ase: 21-hydroxylase; 11-OH-ase: 11-hydroxylase.

\section{Results}

Eight adolescents' girls and young women with variable $\mathrm{CAH}$ were included in this study. Their demographic features were stated in (Table 1). Two sitters with 11-b-hydroxylase deficiency and six with 21 hydroxylase deficiency. Five saltwasting (SW) and one simple virilization (SV). All reported good relations with parents and the experience of having to take responsibility. Parents had similar level of education as well above average income. All had at least one genital surgery (clitorplasty or/and vaginoplasty) with a mean age of one year (range; 3 to 18 months). All had at least an undergraduate education with an average and median $15 \mathrm{y}$.

Our overall results revealed that higher incidence of anxiety, depression (25\%) and withdrawn/depressed behaviour $(25 \%)$ and somatic complaints (75\%). However, female with $\mathrm{CAH}$ felt within the normal range of other parameters.

Only one young female (12.5\%) with 21-hydroxylase deficiency $\mathrm{CAH}$, simple virializing married and had one child, she reported that she is happy in her life. No participants reported suicidal thoughts, or suicidal attempts.

The participants were from a conservative Muslim community who believe that sexuality issues are private and personal, therefor they decided to express their feelings during interview.

\section{Discussion}

Congenital adrenal hyperplasia $(\mathrm{CAH})$ consists of a family of defects in the synthesis of steroid hormones in the adrenal cortex. It is an inborn condition following an autosomal recessive inheritance. More than $90 \%$ of disorders is caused by a deficiency in the enzyme 21 hydroxylase (21OHD), while other forms such $11 \mathrm{~b}$ hydroxylase deficiency (11OHD), and 3beta-hydroxysteroid dehydrogenase deficiency (3 B HSD) compromised the rest $\mathrm{CAH}$ has long term health problems affecting several body systems [1-6].

The diagnosis must be based on history and physical examination supported by the accumulation of ACTHstimulated steroid precursors above the enzymatic block, with 
the exception of lipoid hyperplasia (P450 scc deficiency) in which almost no steroids are produced. Also, an experienced paediatric radiologist, as part of a multidisciplinary team, plays an important role as the sonographic appearance of the adrenal gland, the cerebriform appearance, is characteristic, and the internal genitalia can be determined. This can be supported by other modalities such as genitography, computed tomography (CT) scan, and magnetic resonance imaging (MRI) [1-7].

Thus, the complexity of the disorder (CAH) which can lead to various health problems emphasizes the need for care providers to establish a multidiscipline team approach to minimize both medical and psychological consequences. The team should consist of paediatric endocrinologist, genetics, gynaecologist, urologist, paediatric surgeon, psychologist or psychiatrist, plastic surgeon and specialist nurse. Other discipline should be included according to clinical needs $[5,10,13]$.

Although various studies documented the medical aspect of $\mathrm{CAH}$, yet to our knowledge this is the first psycological study in Saudi Arabia. The aim of this study was to assess the psychological impact of CAH on Saudi Adolescent and young girls, and bring to the attention of the care provider of such need. There were multiple studies worldwide of psychological assessment of adjustment of women with $\mathrm{CAH}$, depend on nature of the methodology used [14-27]. Our patients exhibit high rate of psychopathology disorders. Among the disorders, depression and anxiety [28] were the most prevalent. The relevance of androgens in the development of psychopathology has been suggested based on sex related differences in the prevalence, course and treatment response of several psychiatric disorders [29].

Although, the aetiology of anxiety disorders is not fully understood, evidence from both preclinical and clinical studies support the contribution of corticotropin-releasing hormone (CRH) in the expression of anxiety related disorders, mainly through CRH neuro circuits connecting the amygdala and locus coeruleus. In the $\mathrm{CAH}$ patients increased $\mathrm{CRH}$ secretion is expected in the untreated or undertreated state. This increased $\mathrm{CRH}$ secretion reflects a block in cortisol production leading to an overall elevation in CRH due to lack of feedback inhibition [30]. Shepard et al. [31] found decreased amygdala volume in $\mathrm{CAH}$ patients suggesting that alteration in the hypothalamicpituitary adrenal axis affect the growth and development of amygdala.

The finding of psychological well-adjusted girls with $\mathrm{CAH}$ may be attributed to successful genital surgery, adequate medical treatment, and appropriate social support [7]. Other studies suggested that chronic illness and other difficult life experiences have only temporary effect on adjustment $[32,33]$.

Several studies indicated reduce fertility in women with CAH. Pregnancy rates in patients with salt wasting (SW) $\mathrm{CAH}$ and simple virializing (SV) forms were similar [34]. There are multiple causes for reduced fertility in females with $\mathrm{CAH}$, including improper treatment.

Finally, this study is not without any limitations. Firstly, patients were diagnosed infancy with ambiguous genitalia or salt wasting and reared as females. Therefore, it was not possible to highlights the effects of the wrong sex assignments. Secondly, all participants were selected into our study; these individuals may be relatively healthy and interested in the therapeutics measures provided. Lastly but not the least, the smaller size of the study group (only eight patients) and the limited answers will not allow appropriate and adequate statistical power. However, this article hopefully, will stimulate researchers to design new studies that attempt to model some degree of complexity of lives of children, adolescent, and young adults' women with the disease $\mathrm{CAH}$.

In conclusion, psychological adjustment is variable in females with $\mathrm{CAH}$ who were diagnosed and appropriately reared in early neonatal life. Adjustment depends on the severity of the disease rather than the patient and parent level of education and income.

Future multicentre studies involving $\mathrm{CAH}$ patients in Saudi Arabia is needed to ensure large sample size in addition, further researchers should concentrate on various aspects of psycho-social outcome of CAH in Saudi children.

\section{Acknowledgment}

The authors would like to thank Miss Hadeel N.A. Al-Jurayyan for her help in preparing this manuscript.

\section{References}

1. Speiser PW, White PC. Congenital adrenal hyperplasia. N Engl J Med 2003; 349: 776-788.

2. Lee PA, Houk CP, Ahmed SF, Hughes IA. Consensus statement on management of intersex disorders. International Consensus Conference on Intersex. Pediatrics 2006; 118: 488-500.

3. Al Jurayyan NA. Congenital adrenal hyperplasia in Saudi Arabia. Int J Health Sci Res 2016; 6: 302-310.

4. Reisch N, Arlt W, Krone N. Health problems in congenital adrenal hyperplasia due to 21-hydroxylase deficiency. Horm Res Paediatr 2011; 76: 73-85.

5. Al-Jurayyan NA. Ambiguous genitalia, two decades of experience: clinical management and sex assignment. J Taibah Univ Med Sci 2010; 13-20.

6. Speiser PW, Azziz R, Baskin LS. Congenital adrenal hyperplasia due to steroid 21-hydroxylase deficiency: an endocrine society clinical practice guideline. J Clin Endocrinol Metab 2010; 95: 4133-4160.

7. Ogilvie CM, Crouch NS, Rumsby G, Creighton SM, Liao LM, Conway GS. Congenital adrenal hyperplasia in adults: a review of medical, surgical and psychological issues. Clin Endocrinol 2006; 64: 2-11.

8. Engberg H, Butwicka A, Nordenstrom A. Congenital adrenal hyperplasia and risk for psychiatric disorders in girls and women born between 1915 and 2010: a total population study. Psychoneuroendocrinology 2015; 60: 195-205. 
9. Auchus RJ, Witchel SF, Leight KR. Guidelines for the development of comprehensive care centers for congenital adrenal hyperplasia: guidance from the CARES foundation initiative. Int J Pediatr Endocrinol 2010; 2010: 275213.

10. Grosse SD, Schechter MS, Kulkarni R, Lloyd-Puryear MA, Strickland B, Trevathan E. Models of comprehensive multidisciplinary care for individuals in the United States with genetic disorders. Pediatrics 2009; 123: 407-412.

11. Prader A. Der Genital berfund pseudohermaphroditism feminium des kongenitalen adrenogenitalen syndrome Helven Pedietr Acta 1954; 9: 231-248.

12. Achenback TM, Roscorla LA Manual for ASEBA school age forms and profiles, Research Centre for children, youth, and families. University of Vermont, Burlington, Vt, USA 2001.

13. Moshiri M, Chapman T, Fechner PY. Evaluation and management of disorders of sex development: multidisciplinary approach to a complex diagnosis. Radiographics 2012; 32: 1599-618.

14. Berenbaum SA, Korman Bryk K, Duck SC, Resnick SM. Psychological adjustment in children and adults with congenital adrenal hyperplasia. J Pediatr 2004; 144: 741-746.

15. Idris AN, Chandran V, Zulkifli SZS, Rasat R. Behavioural outcome in children with congenital adrenal hyperplasia: experience of a single centre. Int J Endocrinol 2014.

16. Engberg H, Moller A, Hagenfeldt K, Nordenskjold A, Frisen L. The experience of women living with congenital adrenal hyperplasia: impact of the condition and the care given. Clin Endocrinol 2016; 85: 21-28.

17. Stout SA, Litvak M, Robbins NM, Sandberg DE. Congenital adrenal hyperplasia: classification of studies employing psychological endpoints. Int $\mathrm{J}$ Pediatr Endocrinol 2010; 2010: 191520.

18. Abd Rahman FN, Mohd Daud TI, Nik Jaafar NR, Shah SA, Tan SM, Wan Ismail WS. Behavioral and emotional problems in a Kuala Lumpur childrens home. Pediatr Int 2013; 55: 422-427.

19. Hall CM, Jones JA, Meyer-Bahlburg HF. Behavioral and physical masculinization are related to genotype in girls with congenital adrenal hyperplasia. J Clin Endocrinol Metab 2004; 89: 419-424.

20. De Silva KS, de Zoysa P, Dilanka WM, Dissanayake BS. Psychological impact on parents of children with congenital adrenal hyperplasia: a study from Sri Lanka. J Pediatr Endocrinol Metab 2014; 27: 475-478.

21. Malouf MA, Migeon CJ, Carson KA, Petrucci L, Wisniewski AB. Cognitive outcome in adult women affected by congenital adrenal hyperplasia due to 21hydroxylase deficiency. Horm Res 2006; 65: 142-150.

22. Costello EJ, Egger H, Angold A. Ten-year research update review: the epidemiology of child and adolescent psychiatric disorders: I. Methods and public health burden. J Am Acad Child Adolesc Psychiatry 2005; 44: 972-986.

23. Nermoen I, Husebye ES, Svartberg J, Lovas K. Subjective health status in men and women with congenital adrenal hyperplasia: a population-based survey in Norway. Eur $\mathrm{J}$ Endocrinol 2010; 163: 453-459.

24. Hines M. Psychosexual development in individuals who have female pseudohermaphroditism. Child Adolesc Psychiatr Clin N Am 2004; 13: 641-656.

25. Reisch N, Hahner S, Bleicken B. Quality of life is less impaired in adults with congenital adrenal hyperplasia because of 21-hydroxylase deficiency than in patients with primary adrenal insufficiency. Clin Endocrinol (Oxf) 2011; 74: 166-173.

26. De zoya. Clinical psychology in a medical setting in Asian country: current situation and way forward in Sri Lanka. Int Psych 2013; 10: 18-19.

27. Malouf MA, Inman AG, Carr AG, Franco J, Brooks LM. Health-related quality of life, mental health and psychotherapeutic considerations for women diagnosed with a disorder of sexual development: congenital adrenal hyperplasia. Int J Pediatr Endocrinol 2010; 2010: 253465.

28. Ford T, Goodman R, Meltzer H. The British Child and Adolescent Mental Health Survey 1999: the prevalence of DSM-IV disorders. J Am Acad Child Adolesc Psychiatry 2003; 42: 1203-1211.

29. Mueller SC, Ng P, Sinaii N, Leschek EW, Green-Golan L, VanRyzin C. Psychiatric characterization of children with genetic causes of hyperandrogenism. Eur $\mathrm{J}$ Endocrinol 2010; 163: 801-810.

30. Merke DP, Fields JD, Keil MF, Vaituzis AC, Chrousos GP, Giedd JN. Children with classic congenital adrenal hyperplasia have decreased amygdala volume: potential prenatal and postnatal hormonal effects. J Clin Endocrinol Metab 2003; 88: 1760-1765.

31. Shepard JD, Barron KW, Myers DA. Corticosterone delivery to the amygdala increases corticotropin-releasing factor mRNA in the central amygdaloid nucleus and anxiety-like behavior. Brain Res 2000; 861: 288-295.

32. Kuhnle U, Bullinger M, Schwarz HP. The quality of life in adult female patients with congenital adrenal hyperplasia: a comprehensive study of the impact of genital malformations and chronic disease on female patients life. Eur J Pediatr 1995; 154: 708-716.

33. Noll RB, Vannatta K, Koontz K, Kalinyak K, Bukowski WM, Davies WH. Peer relationships and emotional wellbeing of youngsters with sickle cell disease. Child Dev 1996; 67: 423-436.

34. Hagenfeldt K, Janson PO, Holmdahl G, Falhammar H, Filipsson H, Frisén L, Thorén M, Nordenskjold A. Fertility and pregnancy outcome in women with congenital adrenal hyperplasia due to 21-hydroxylase deficiency. Hum Reprod 2008; 23: 1607-1613. 
Psychological impact of congenital adrenal hyperplasia on adolescent and young girls in Saudi Arabia

*Correspondence to

Nasir A. M. Al-Jurayyan

Department of Paediatrics

College of Medicine

King Saud University

Saudi Arabia 